Editorial

\title{
Sustained Growth of the Impact Factors of MDPI Open Access Journals
}

\section{Dietrich Rordorf}

MDPI AG, Postfach, Basel CH-4005, Switzerland; Office: Kandererstrasse 25, Basel CH-4057, Switzerland; E-Mail: rordorf@mdpi.com; Tel.: +41-61-683-77-34; Fax: +41-61-302-8918

Received: 2 January 2012 / Published: 2 February 2012

Following the tradition established during the past two years [1,2], we are pleased to report the newly released Impact Factors of MDPI open access journals by the means of an editorial. This year's edition of the Journal Citation Reports (JCR), which is published annually by Thomson Reuters, includes seven journals published by MDPI, including three that received their first official Impact Factors - Energies, Entropy, and more surprisingly Viruses - the latest with citation data from 2009 only. We are pleased to announce that the continued growth in Impact Factors reported during the past two years has been sustained, and Impact Factors of MDPI journals continue on a growth path. Table 1 reports the latest Impact Factors for 2010. Figure 1 graphically depicts the evolution of the Impact Factors for the four MDPI open access journals that have received Impact Factors in the past. Table 2 reports the ranking of the MDPI journals within the subject categories of the Science Citation Index Expanded (SCIE).

Table 1. Impact Factors of seven MDPI journals [adapted from the Journal Citation Reports (JCR), Edition 2010, Copyright 2011 by Thomson Reuters].

\begin{tabular}{lcccc|c}
\hline & $\mathbf{2 0 0 6}$ & $\mathbf{2 0 0 7}$ & $\mathbf{2 0 0 8}$ & $\mathbf{2 0 0 9}$ & $\mathbf{2 0 1 0}$ \\
\hline Energies & & & & & 1.130 \\
Entropy & & & & & 1.109 \\
IJMS & 0.679 & 0.750 & 0.978 & 1.387 & 2.279 \\
Marine Drugs & & 1.103 & 1.200 & 2.863 & 3.471 \\
Molecules & 0.841 & 0.940 & 1.252 & 1.738 & 1.988 \\
Sensors & 1.373 & 1.573 & 1.870 & 1.821 & 1.771 \\
Viruses & & & & & 1.000 \\
\hline
\end{tabular}


Figure 1. Evolution of the Impact Factors for four MDPI open access journals [adapted from the Journal Citation Reports (JCR), Edition 2010, Copyright 2011 by Thomson Reuters].

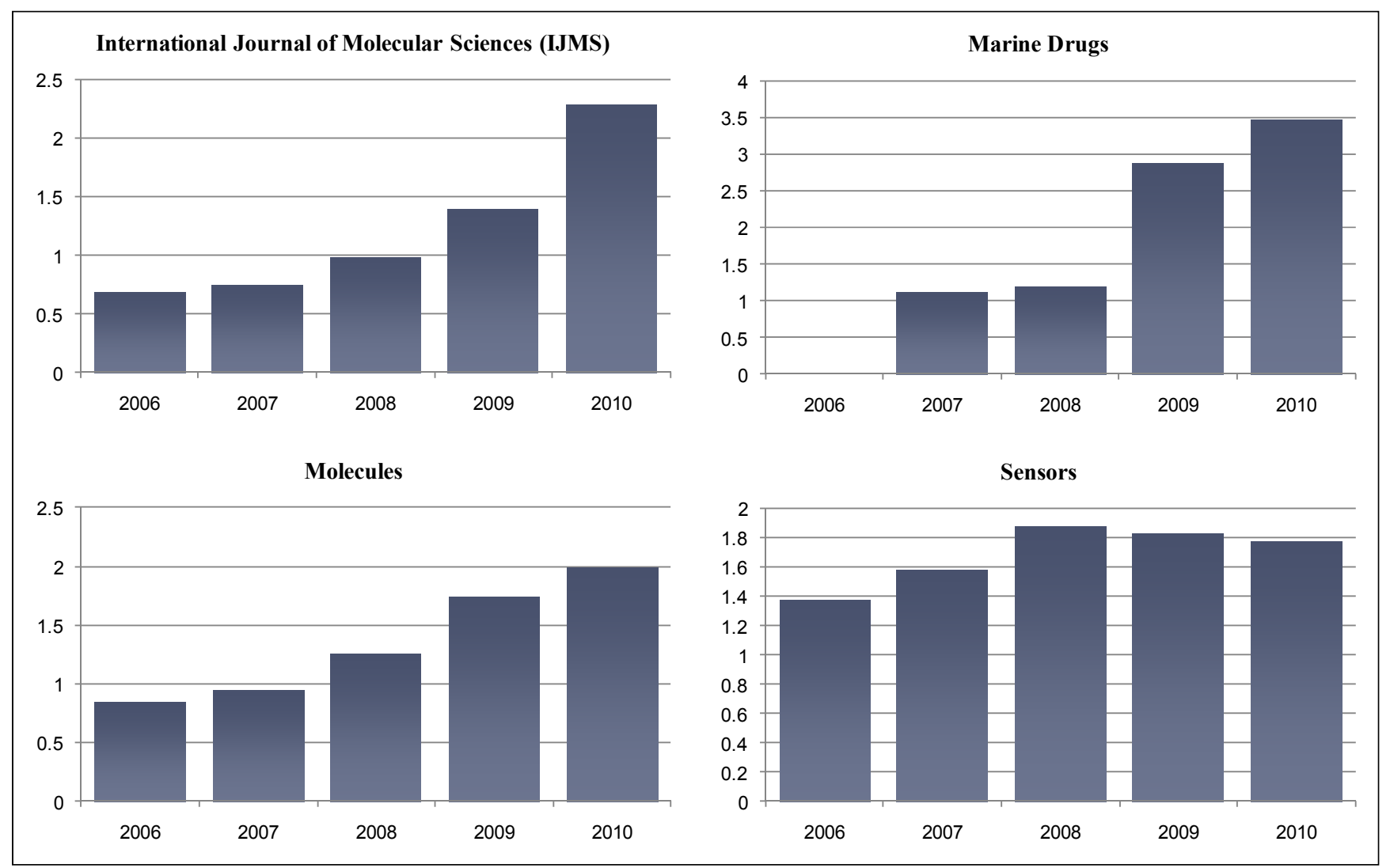

Table 2. Rankings of MDPI open access journals by subject categories.

\begin{tabular}{lll}
\hline Journal & Rank & Category \\
\hline Energies & $42 / 78$ & ENERGY \& FUELS \\
\hline Entropy & $34 / 80$ & PHYSICS, MULTIDISCIPLINARY \\
\hline IJMS & $40 / 144$ & CHEMISTRY, MULTIDISCIPLINARY \\
\hline Marine Drugs & $9 / 54$ & CHEMISTRY, MEDICINAL \\
\hline Molecules & $27 / 56$ & CHEMISTRY, ORGANIC \\
& $14 / 61$ & INSTRUMENTS \& INSTRUMENTATION \\
Sensors & $16 / 26$ & ELECTRO-CHEMISTRY \\
& $38 / 71$ & CHEMISTRY, ANALYTICAL \\
\hline Viruses & $29 / 32$ & VIROLOGY \\
\hline
\end{tabular}

The sustained and continued growth of the Impact Factors of MDPI journals provides further evidence for the citation advantage of the full open access policy, which was instituted for all MDPI journals in early $2007[3,4]$. 


\section{References}

1. Lin, S.-K. Full Open Access Journals Have Increased Impact Factors. Molecules 2009, 14, 2254-2255; doi:10.3390/molecules14062254.

2. Rordorf, D. Continued Growth of the Impact Factors of MDPI Open Access Journals. Molecules 2010, 15, 4450-4451; doi:10.3390/molecules15064450.

3. Lin, S.-K. Full Open Access Publishing Policy Imposed in 2007: Molecules Publishes Many More Papers This Year - More than 2000 Pages Published up to Issue 8. Molecules 2007, 12, 2001-2002; doi:10.3390/12082001.

4. Lin, S.-K. Non-Open Access and Its Adverse Impact on Molecules. Molecules 2007, 12, 1436-1437; doi:10.3390/12071436.

(C) 2012 by the authors; licensee MDPI, Basel, Switzerland. This article is an open access article distributed under the terms and conditions of the Creative Commons Attribution license (http://creativecommons.org/licenses/by/3.0/). 